\title{
Risk Management in Hydrogen Technologies - Application for Mobile Technology
}

\author{
Juraj Sinay ${ }^{1}$ \\ Branislav Konečný2 \\ email: branislav.konecny@tuke.sk
}

Technical University of Košice, Faculty of Mechanical Engineering, Department of Safety and Quality, Letná 9, 04200 Košice, Slovak Republic

\begin{abstract}
Hydrogen technologies will play a key role in the near future in maintaining transport and mobility sustainability. The technical solutions used in hydrogen technology use many common elements from "traditional" types of propellant fossil fuel. However, the specific chemical, biological and physical properties of hydrogen require different approaches in construction and design. These specific properties also entail possible safety risks resulting from inadequate knowledge in this area. In order to minimize them, it is necessary to know these technologies also in terms of possible threats and to create a system for their early identification, minimization or elimination.
\end{abstract}

Keywords: hydrogen, safety, mobile application,

\section{Introduction}

Hydrogen is the fuel of the future. It has been proved by the development of alternative fuels so far to be the most promising fuel. It has several properties that make it preferable to other fuels. The main advantage is that it occurs in the whole universe - therefore, it is possible to obtain in virtually unlimited quantity.

In order to create an integrated security model for hydrogen technology, it is necessary to take into account all aspects of this source of energy and the specifics of its operation.

The proportion of alternative fuel powered cars to the total amount of new cars purchased in the EU has been rising steadily over the last few years (in $2016+$ $4.1 \%$ compared to 2015). In connection with the forthcoming legislative measures for air protection from toxic emissions, it can be assumed that this trend will con- 
tinue until most of the cars sold in the EU will be equipped with some kind of alternative propulsion system or classical fossil fuel propulsion system with substantially reduced emissions.

\section{Alternative types of mobile devices}

Currently, the following types of alternative propulsion systems are present on the market - Fig. 1. This group includes the types of propulsion systems based on the classical concept of internal combustion engines using synthetic fuels or different types of biofuels, production of which contributes to conditions for minimizing emissions, especially $\mathrm{CO} 2$.

Figure 2 shows the diagrams of the most frequently used and prospective types of propulsion systems. These are classical fossil fuel propulsion systems - Fig. 2a, with hybrid propulsion - Fig. 2b, with electric propulsion - Fig. 2c and hydrogen fuel cell propulsion - Fig. 2 d. 


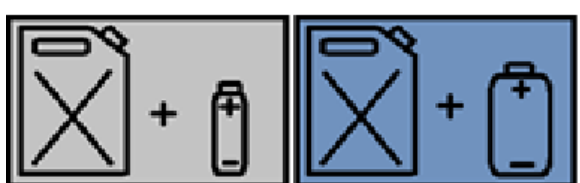

1. A mild hybrid vehicle ( $\mathrm{mHEV}$ ) is not capable

of running purely on electric energy. The propulsion system is set to turn the combustion engine off and disconnect it from the drive, e.g. when coasting allowing the car to move without gas. It also regenerates energy while braking and uses support the combustion engine during its high performance mode. term 'hybrid' people usually denote a full of the two kinds of propulsion systems independently (i.e. their combination) A full hybrid vehicle may cover several kilometres when operating in pure electric propulsion mode.

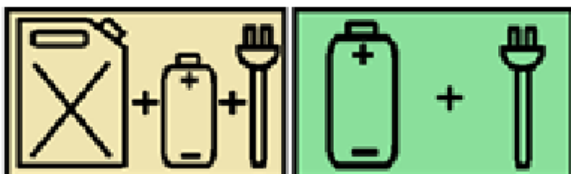

3. Plug-in-hybrid (HEV). When using the vehicle - (PHEV) is a

full hybrid vehicle, which can be charged by an

4. All electric vehicle (BEV) Is an accumulator hybrid electric vehicle. It external source of can be propelled by each energy. They have higher capacity batteric enabling to cover a longer distance - more $\begin{array}{ll}\text { electric power or } & \text { than } 100 \mathrm{~km} \text { by using } \\ \text { combustion engine or by } & \text { pure electric power. }\end{array}$

\section{electric vehicle}

(electromobile)

representing a remarkable step in e-

mobility since classical internal combustion

engine is no more

needed there

Improvement of

accumulator technology and investment in the development of charging infrastructure will make the electromobiles a more viable alternative even for long-distance

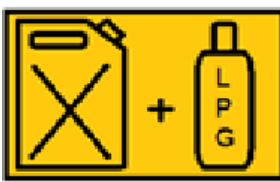

5. Liquefied Petroleum Gas (LPG) - it has been used as an alternative to the petrol engines for decades. It is usually a converted classical petrol engine aggregate combined with the gas system kit. Such a car can run on petrol or gas independently. Longer distance drive is the advantage of such combination of both propulsion systems. Currently, there are more manufacturers producing LPG cars.

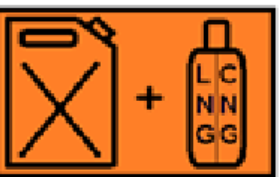

6. Compressed Natural 7. Hydrogen $(\mathrm{H} / \mathrm{H} 2)-$ Gas (CNG) / Liquefied is currently one of the Natural Gas (LNG) - is purest kinds of a combination of classical petrol combustion engine and additional gas equipment. Sometimes, cars are rebuilt additionally, converted or there is a wide range of car models produced by various car manufacturers. These cars usually have a reduced petrol tank to provide more space for high-pressure natural gas tanks combustion engine or in fuel cells. Higher risk related to operation of such vehicles result from specific properties of hydrogen. Currently, there are only about 50 hydrogen refuel stations in the EU.

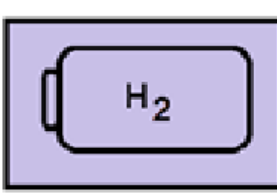

journeys.

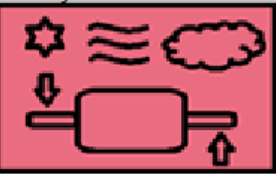

8. Various well-known solutions, such as compressed air propulsion system, alternative propulsion systems. The hydrogen engine generates only pure water vapor and oxygen. There are two possible ways of its use

flywheels, propulsion systems using biomaterials, biowaste or various chemical compounds.

Fig.1 Types of alternative propulsion systems [1]

Classical propulsion systems using fossil fuels (Fig. 2A) typically apply a front position of the engine allowing a bigger passenger space. They also allow an appropriate crumple zones dimensioning for controlled structure deformations. The 
engine and component layout options are aimed to create the most compact engine and transmision unit including the complete equipment.

Hybrid drives - Fig. 2B use the basic concept of classical internal combustion engines. They are complemented by components that enable the movement of the vehicle powered by an alternative type of energy. Typically, it is electric power that is used to drive at low speeds depending on battery size, most frequently while driving in the city and as a support during high performance mode, e.g. overtaking
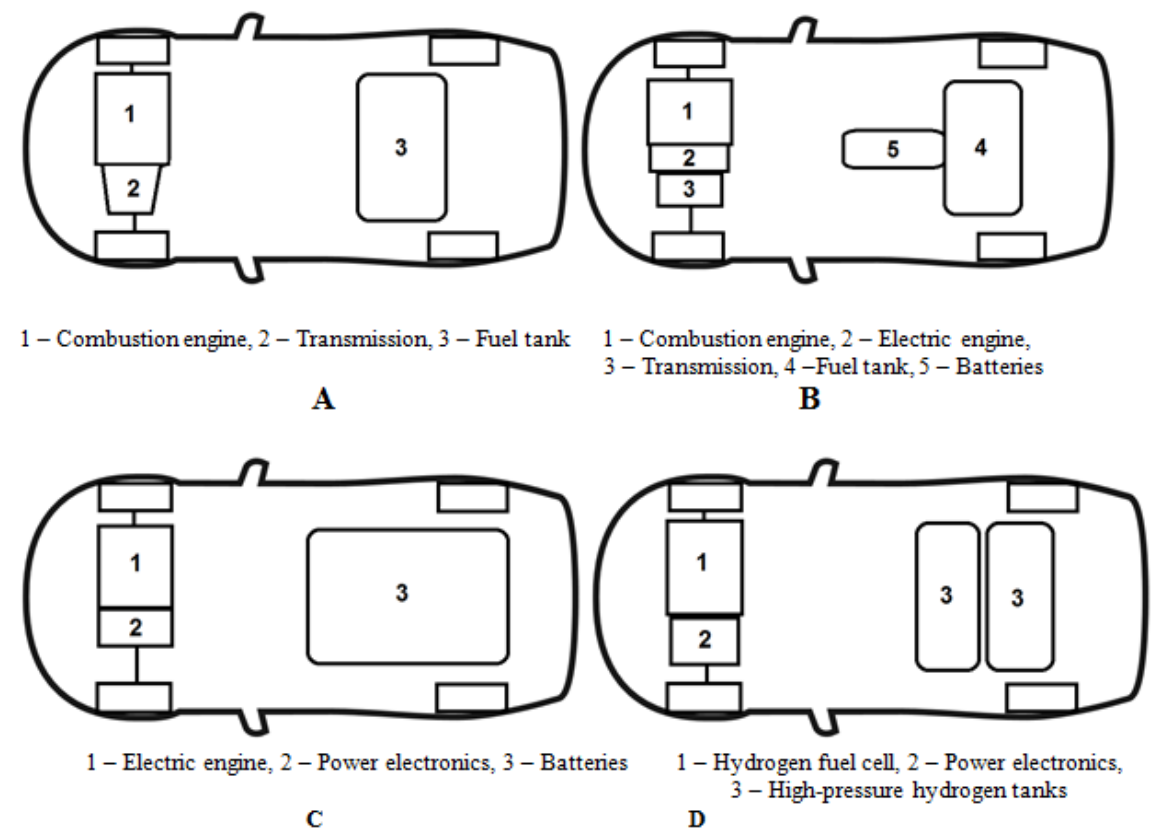

Fig. 2 Propulsion systems diagram

Electric propulsion systems - Fig. 3C use a different concept from conventional propulsion systems. The placement of the components is partly approaching them. The batteries as a vehicle power source is stored in the rear part on the floor, or occupy the whole floor area under the seats.

Hydrogen propulsion systems - Fig. 2D are currently the least common. However, they represent a promising alternative to the classical propulsion type. They use fuel cells, which are most often placed under the front hood, where an electric motor for the transmission of torque is also placed to drive the car's wheels. Highpressure tanks are located under the floor at the rear of the car, and may be divided into several bundles as required. 
However, the use of hydrogen represents specific risks that have not yet been precisely defined or analysed. High-pressure hydrogen tanks create high demands especially on construction of the high-pressure components of the car's fuel system. The disadvantage is a gradual degradation of fuel cells, which increases during long-term shutdown. During servicing of these cars, it is necessary to take into account the possibility of explosion caused by mixing of hydrogen with oxygen. Ecological and silent operation of hydrogen-powered cars without the direct creation of toxic emissions, especially $\mathrm{CO} 2$ and $\mathrm{NOx}$ is the benefit. The actual refuelling of hydrogen is time-comparable to fossil fuel engines, which is an advantageous feature playing in favour of hydrogen within the group of alternative propulsion systems.

Automotive engineers are trying to incorporate hydrogen propulsion systems into bodyworks used for conventional internal combustion engines (except for prototypes and models developed for this type of drive). The advantage of this solution is a smaller number of unified parts and associated lower development, production and maintenance costs. Depending on spatial options, some design solutions do not interfere with the interior of a vehicle more than would be in the case of fossil fuel propulsion system. Others create limitations in the form of reduced luggage space. Some drive components remain unchanged from the classical internal combustion engine version. Others are specific to the hydrogen propulsion system. [2] 


\section{Generating electricity in hydrogen fuel cells}

The conversion of energy contained in hydrogen into fuel cells to electricity has proven to be a prospect for the mobile technology of the future. The most important reason is that such a change makes smaller losses than the actual combustion of hydrogen in a normal combustion engine, moreover, the operation of fuel cells is more efficient than the operation of internal combustion engines running on fossil fuels. A great advantage of this propulsion alternative is almost no-emission operation - it only emits clean water and heat. Omission of several friction pairs represents an unquestionable advantage. Depending on the design, the use of gearbox and differential is omitted. Electronics can do this job. The disadvantage is that the system itself requires a completely new design, the original body and chassis remains - but its design also requires some change.

At present, almost every renowned car manufacturer has a vehicle powered by hydrogen fuel cell or at least a prototype of this kind in its production program.

Fuel cell function principle - Fig. 3 is based on an artificially formed hydrogen and oxygen molecule on different sides of the fuel cell membrane. On the surface of the membrane, these molecules are cleaved by the action of a catalyst. The positively charged hydrogen ions transfer the electron to the electrode and pass through the membrane to the second electrode. They merge with the anions of oxygen and create water, which releases heat. The electrodes are guided by external conduit from the impermeable membrane and become a source of electrical energy that drives, for example, an electric motor, recharges batteries or capacitors. The engineers are trying to make cars powered by hydrogen fuel cells available, environmentally friendly and especially safe in any situation that may occur during operation [3]. 


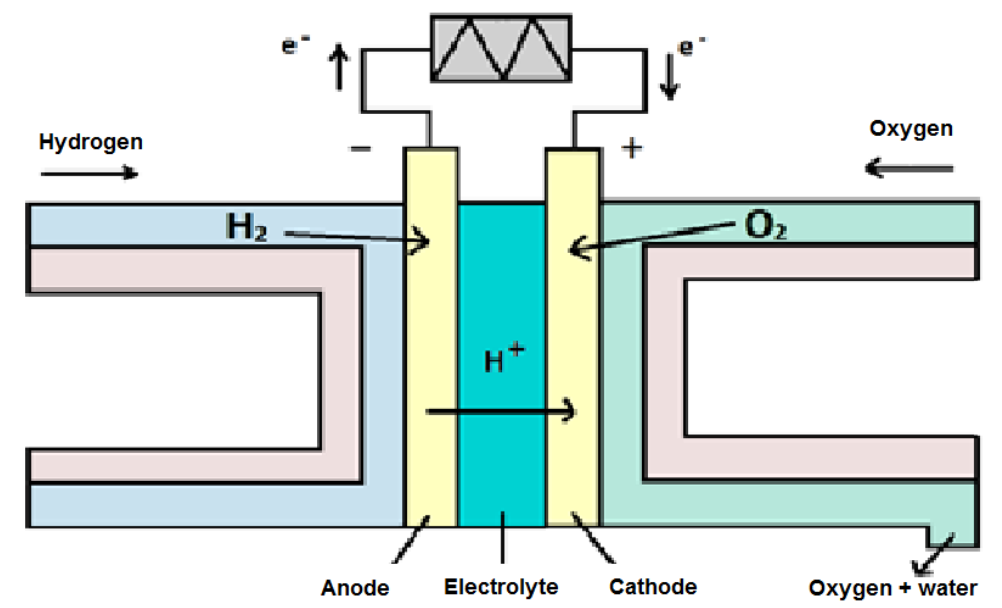

Fig. 3 The principle of hydrogen fuel cell operation

\subsection{The concept of hydrogen propulsion}

The hydrogen propulsion system itself can be divided into several units. Fig. 4 shows the diagram of the experimental hydrogen propulsion in the B \& S 5 designed at the Technical University of Košice. 


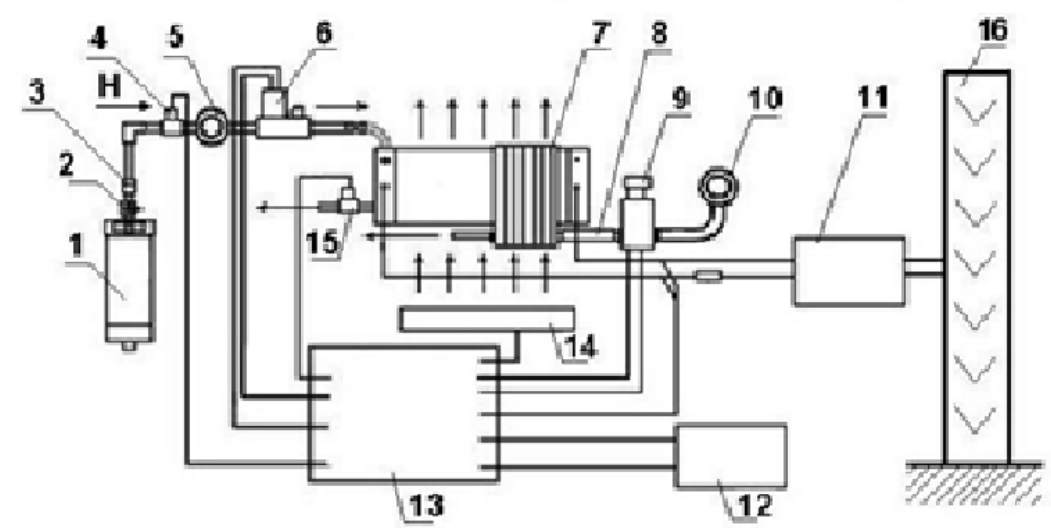

1. hydrogen tank, 2 - ball valve, 3 - quick coupling, 4 - electromagnetic inlet valve, 5 - control valve, 6 - mass flowmeter, 7 - fuel cell, 8 - air inlet, 9 - compressor, 10 - air filter, 11 - electric motor with sensors, 12 - hydrogen leak detector, 13 - control unit, 14 - axial fan, 15 - hydrogen outlet, 16 - powered wheel

Fig. 4 Basic Scheme of B \& S Hydrogen Drive 5 Jeep Willys [4]

The first part includes the filler neck and high-pressure tanks with accessories. The second part consists of feed pipes, fuel cells and power electronics. The third part includes voltage transducers of electric motor to the driving power itself. In some cases there are also batteries and chassis accessory components. Each set contains a filler neck. It is most often located at the place where the fossil fuels filler neck is traditionally placed. Its task is to completely close the hydrogen tank during operation and allow the hydrogen to enter the tank at the appropriate time during pumping. The filler necks are usually equipped with a sensor that sends a signal to the control unit of the propulsion system to prevent the possibility of a car starting to move with the attached fuel nozzle and a potential threat to passengers and people around the service station. Hydrogen tank is necessary in the system. Since hydrogen has a large volume in proportion to its weight, compression to a relatively high pressure is required for its efficient storage. For this reason, the tanks must be solid and must be of a sufficient durability. Their weight is their disadvantage, which is much higher compared to fossil fuels cars.

At present, there are four basic types of high pressure tanks. They differ in materials and design. They are equipped with a one-way and solenoid valve, in some 
cases also with a manual valve which, in the event of a solenoid valve failure, allows the supply to be stopped or hydrogen released. Because of their dimensions and the requirement for maximum safety, they are placed under the floor at the rear seats. The pipeline transfers hydrogen from the tank to the unit that supplies hydrogen to the fuel cell. Most often, they are made of various kinds of steel to meet the durability requirements. They must be hydrogen embrittlement proof. Fuel cells make it possible to convert chemical energy contained in hydrogen into electrical energy without the need for thermal or mechanical transformation. Each fuel cell consists of a positive and a negative electrode, between which an electrolyte is located. Low-temperature and high-temperature fuel cells exist in terms of operating temperatures. The electric motor fulfills the function of converting electric to mechanical power enabling movement of the car. Different types of electric motors are used depending on their location, number, car use, etc. The highvoltage battery delivers the necessary electrical energy to initiate the reaction in the fuel cells. Its location depends on spatial requirements and possibilities of the car. Radiator and the coolant tank are not necessary. They are installed depending on the need to cool the fuel cells. Fig. 5 shows the diagram of hydrogen drive.

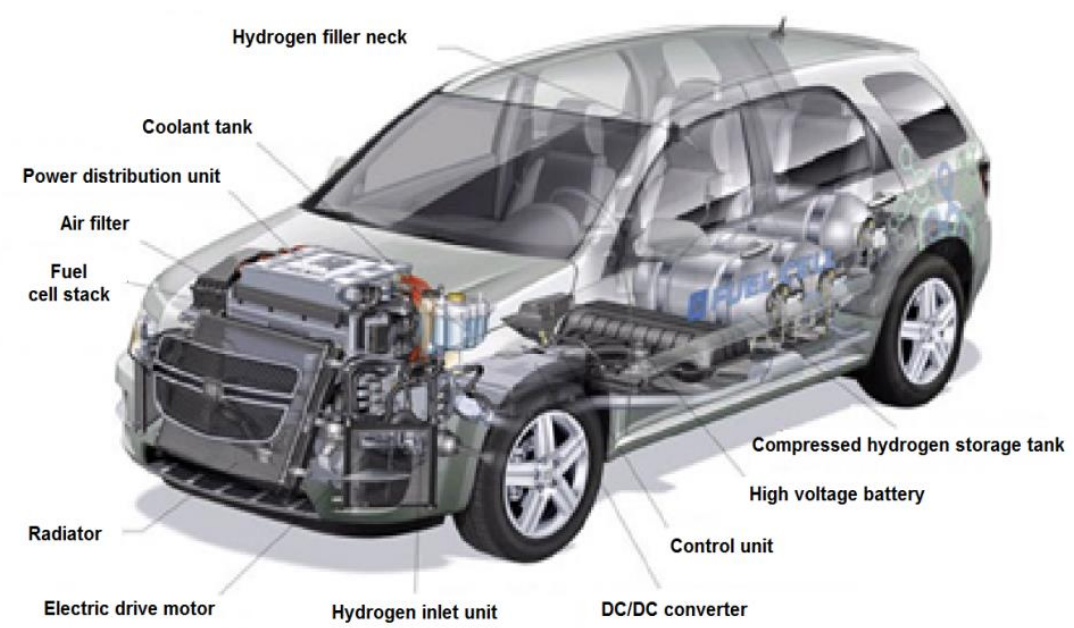

Fig. 5 The concept of hydrogen fuel cell vehicle (GM HydroGen4) [5] 


\section{Risks related to operation of vehicles with hydrogen propulsion system}

Mobile devices are characterized by specific risks arising from their ability to change their position depending on the need of the driver, passengers. This creates a potential threat not only for the car and its servicing (in this case, also for the passengers) as regards to the Safety category, but also for the area that is in the close proximity to the automobile. It is therefore necessary to take into account their possible threat to civil society in the design of hydrogen-powered vehicles security.

Car owners will demand the same benefits and practicality (such as downhill, fast fueling, parking over / under-ground garages, reliability), as is the case with current cars. At the same time, the risk must be the same as or lower than for fossil fuel powered cars.

Hydrogen propulsion engineers must take account of hydrogen risk factors already in the design phase of the vehicle as well as in the selection of used materials. It is necessary for the owner of a hydrogen-powered car to safely use its properties, without having to know and control hydrogen technology and fuel cell technology. However, there is a need to avoid unintentional accidents resulting from unawareness of the risk of hydrogen use during car driving, parking, repairs and recycling.

Vehicle accident represents an important area for identifying dangers as a part of risk management. In this case, uncontrolled leakage of hydrogen could result in a considerable material and financial damage or damage to human health and life. The high-pressure tanks of vehicles used in the current hydrogen cars reach the capacity of up to 8 kilograms of hydrogen compressed at a pressure of approximately $70 \mathrm{MPa}$. This pressure, together with high explosiveness and hydrogen flammability, poses an increased risk with the use of such technologies in trucks or buses since they require a larger impact area to be counted on in the event of hydrogen leakage.

As for leakage of hydrogen, several accident scenarios can be associated with leakage of this dangerous substance. Vehicles using hydrogen fuel cells will be parked in publicly accessible parking spaces including covered garages and homes. It is also necessary to assume the potential intentional misuse of negative properties of hydrogen by persons to destroy property and health.

Repair and recycling of hydrogen powered cars will bring new specific problems and will also require a different approach in some procedures such as tank replacement, refuelling, and the post-accident repair. Unprofessional application of operating procedures, the use of unoriginal, inappropriate spare parts that do not meet the required material standard can be considered as significant threat.

\subsection{Risk analysis of mobile applications using hydrogen media}


Properties characteristic to hydrogen as a fuel or energy carrier define technical and operational measures to minimize the risks arising from hydrogen propulsion system operation:

1 - risk of burning, ignition, explosion

2 - risk of overpressure,

3 - low temperature risk

4 - risk due to hydrogen embrittlement,

5 - risk as a consequence of the effect of hydrogen on the human organism [3]

Flammability risk - represents the basic risk of the hydrogen system. For hydrogen, it is highly probable that it will leak due to its physical and chemical properties. The leakage is directly related to the formation of a combustible mixture and can lead to ignition and explosion. Its flame speed, which is higher than with fossil fuels, represents a significant factor.

The risk of overpressure - is conditioned by the fact that high-pressure values are applied in hydrogen storage. As a result, all components ensuring the implementation of storage technology are situated in the high-pressure area throughout their lifecycle, the result of which is hydrogen embrittlement.

Temperature risk - occurs when cooling hydrogen to liquid hydrogen $\left(-253^{\circ} \mathrm{C}\right)$. When cooling the surrounding materials, there are substantial changes in the solidity properties that could result in damage in the material structure.

Hydrogen embrittlement - is a property that occurs under specific conditions. The materials of high-pressure tanks or other devices can lose their structural resistance over long periods of time in contact with hydrogen. The factors that affect it can be classified as follows - type of material, hydrogen concentration, hydrogen pressure, temperature, mechanical stress, pressure change, grain diameter, microstructure and heat treatment history, moisture contained in hydrogen. [6]

Effect of hydrogen on human body - direct contact with gaseous or liquid hydrogen can result in local anesthesia up to freezing. Burning hydrogen which creats a high temperature and a specific flame also represents a health risk. Hydrogen is not toxic, but there is a risk of choking, especially in confined spaces, such as inside the car body.

It can be said that the possibility of hydrogen leakage outside the specified working environment represents the greatest risk. Explosive mixture is created and it requires only minimal energy to initiate an explosion.

All of the above mentioned risks also have an impact on Security because of hydrogen technology failure - especially when using this technology in the transport means, may involve a high number of people at risk. Cars can get virtually anywhere during their operation - and the increased risk will be mainly their movement in densely populated areas. 
3.2 Analysis and assessment of risks within the complex chain used during the operation of hydrogen powered car

The main areas where risk analysis is needed can be divided into:

- hydrogen production

- transport and distribution, transport by road, rail, pipeline, petrol stations

- hydrogen storage (liquid and compressed hydrogen)

- hydrogen-powered vehicles (passenger cars, trucks, service)

- tunnels, public car parks, underground parking and private garages

- portable or permanently installed applications using hydrogen

To identify the negative phenomenon (danger) as the first step in the risk analysis, it is best to use the Fault Tree Analysis (FTA), the Failure Mode and Effect Analysis (FMEA), Event Tree Analysis (ETA) which can be appropriately combined with other types of analysis, such as the What if? Method (What If?) for the most comprehensive identification of critical elements. Fig. 6 and 7 show examples of analyzes using the above mentioned methods.

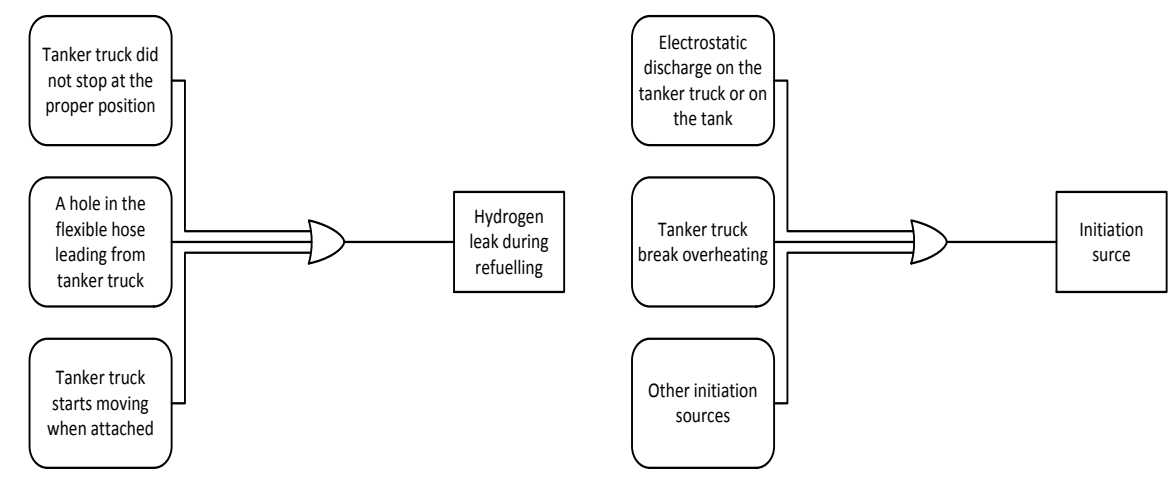

Fig.6 Examples of FTA for hydrogen leak during refuelling from the cistern and for initiation source origin 


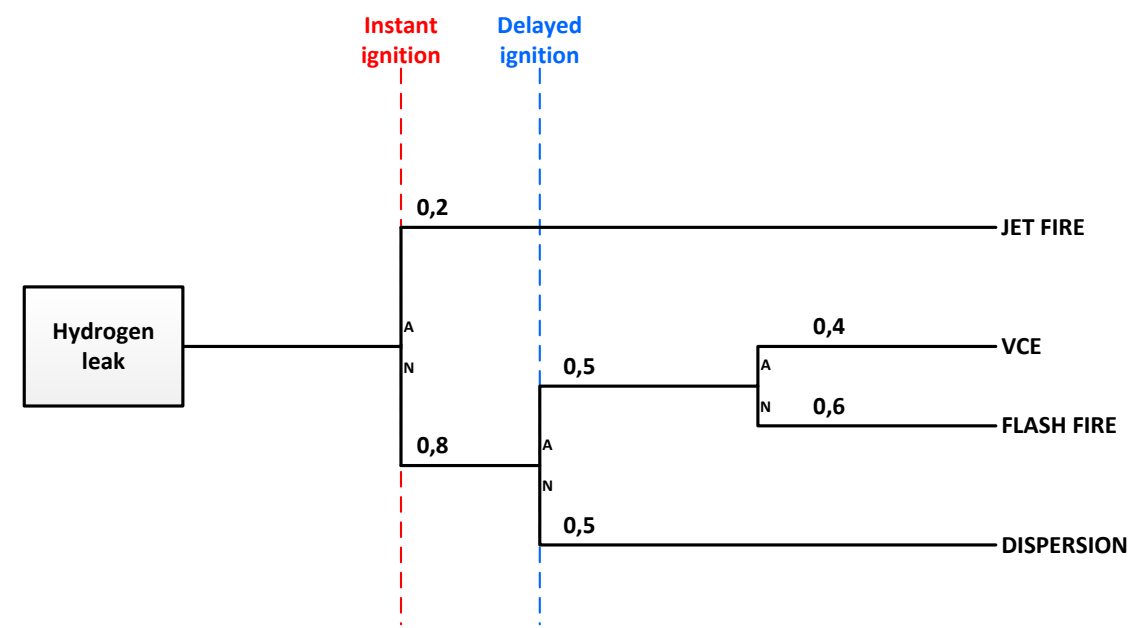

Fig.7 ETA analysis examples for the incident of hydrogen leak during refuelling from the tank - a hose rupture

Subsequent risk assessment is based on an estimate of its basic probability parameters and the impact of negative phenomenon [6] occurring in all areas within the complex chain used during the use of a hydrogen-powered car.

Tab. 1 and tab. 2 show quantitative factor values for probability of negative phenomenon occurrence and its consequences. Tab. 3 shows the matrix that assigns a value to each risk.

Tab.1 Occurence probability of an incident

\begin{tabular}{|c|c|c|}
\hline Probability class & $\begin{array}{c}\text { Incident existence fre- } \\
\text { quency }\end{array}$ & $\begin{array}{c}\text { Value assigned to } \\
\text { risk estimation }\end{array}$ \\
\hline Low occurence & $\leq 9,9.10-6$ & 1 \\
\hline Moderate occurence & $1.10-5-9,9.10-4$ & 2 \\
\hline High occurence & $\geq 1.10-3$ & 3 \\
\hline
\end{tabular}

Tab. 2 Negative phenomenon impact

\begin{tabular}{|c|c|}
\hline Negative phenomenon impact & $\begin{array}{c}\text { Value assigned to } \\
\text { risk estimation }\end{array}$ \\
\hline $\begin{array}{c}\text { Death of persons (Maximal injury), } \\
\text { damage to property over 100 000 }\end{array}$ & 5 \\
\hline Severe injury of persons, & 4 \\
\hline
\end{tabular}




\begin{tabular}{|c|c|}
\hline damage to property from 70000 to $100000 €$ & 3 \\
\hline $\begin{array}{c}\text { Medium injury of persons, } \\
\text { damage to property from } 40000 \text { to } 70000 €\end{array}$ & 2 \\
\hline $\begin{array}{r}\text { Minor injury of persons, } \\
\text { damage to property from } 20000 \text { to } 40000 €\end{array}$ & 1 \\
\hline $\begin{array}{r}\text { Without injury of persons, } \\
\text { damage to property below } 20000 €\end{array}$ & \\
\hline
\end{tabular}

Tab. 3 Risk matrix based on [1]

\begin{tabular}{|c|c|c|c|c|c|}
\cline { 2 - 7 } \multicolumn{1}{c|}{} & \multicolumn{5}{c|}{ Negative phenomenon impact } \\
\hline Incident origin probability & 5 & 4 & 3 & 2 & 1 \\
\hline 3 & 8 & 7 & 6 & 5 & 4 \\
\hline 2 & 7 & 6 & 5 & 4 & 3 \\
\hline 1 & 6 & 5 & 4 & 3 & 2 \\
\hline
\end{tabular}

\subsection{Risk management scheme with measures taken for their management}

For practical application of a risk management system for the hydrogen mobile machinery / automobiles, a procedure specified in Tab.4 has been designed for selected types of risks that are most significant based on [1] for hydrogen powered systems.

It is based on the definition of the process or subject for which the risk management system is applied and the performed activity described. Frequency of existence / impact of a negative event based on Tab. 1 is defined here.

Consequently, the respective values of the individual risk variables are assigned based on the Tab. 1 - Probability - P and based on the Tab. 2 Consequence, so that they can be applied to estimate its resulting value - R.

As for the effective draft of measures to minimize or eliminate risks listed in the last column of the Tab.4, the table also includes the description of the respective negative event impact.

Such a risk management model can also be applied in intelligent management systems in the context of industrial strategy 4.0 [3].

Presents the risks in a systematic order for the selected stages of application of hydrogen technology [1]. 


\begin{tabular}{|c|c|c|c|c|c|c|c|c|}
\hline PROCESS & $\begin{array}{l}\text { OPERATION / } \\
\text { DEVICE }\end{array}$ & $\begin{array}{c}\text { FAILURE } \\
\text { OCCURENCE } \\
\text { FRQUENCY }\end{array}$ & UNIT & IN & FROM & $\begin{array}{c}\text { IMPACT } \\
\text { CHARACTER }\end{array}$ & No.P. & MEASURES \\
\hline PUMPING & $\begin{array}{l}\text { Connecting hose } \\
\text { (human error) }\end{array}$ & $2,1.10-3$ & $\begin{array}{c}\text { incident- } \\
1\end{array}$ & 3 & 4 & $\begin{array}{l}\text { Possible hy- } \\
\text { drogen leak, } \\
\text { perniosis, } \\
\text { possible initi- } \\
\text { ation }\end{array}$ & 7 & $\begin{array}{l}\text { Specialized } \\
\text { trainings for } \\
\text { operators, safe } \\
\text { bottling zone } \\
\text { demarcation, } \\
\text { improper as- } \\
\text { semblage pro- } \\
\text { tection system, } \\
\text { hydrogen leak- } \\
\text { age detection, } \\
\text { automatic } \\
\text { pump stop sys- } \\
\text { tem, power } \\
\text { supply backup, } \\
\text { specialized op- } \\
\text { erator train- } \\
\text { ings, redundant } \\
\text { protection so- } \\
\text { lution. }\end{array}$ \\
\hline 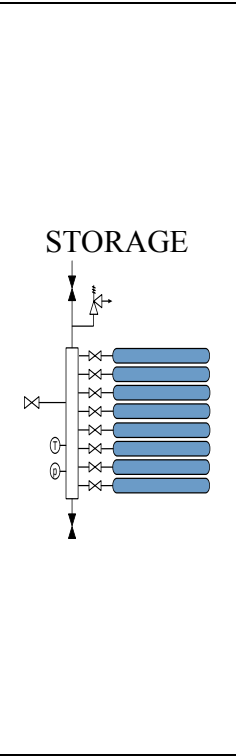 & $\begin{array}{l}\text { Storage tank - rup- } \\
\text { ture }\end{array}$ & $5.10-7$ & year-1 & 1 & 5 & $\begin{array}{l}\text { Possible hy- } \\
\text { drogen leak, } \\
\text { possible initi- } \\
\text { ation, impact } \\
\text { by fragments }\end{array}$ & 6 & $\begin{array}{c}\text { Explosion- } \\
\text { proof construc- } \\
\text { tion, definition } \\
\text { of safe storage } \\
\text { zone, use of } \\
\text { multi- } \\
\text { parametric di- } \\
\text { agnostics for } \\
\text { detection of } \\
\text { tank damage, } \\
\text { suitable choice } \\
\text { of tank materi- } \\
\text { als, use of new } \\
\text { storage con- } \\
\text { cepts without } \\
\text { the need for } \\
\text { high pressure } \\
\text { (e.g. storage }\end{array}$ \\
\hline
\end{tabular}




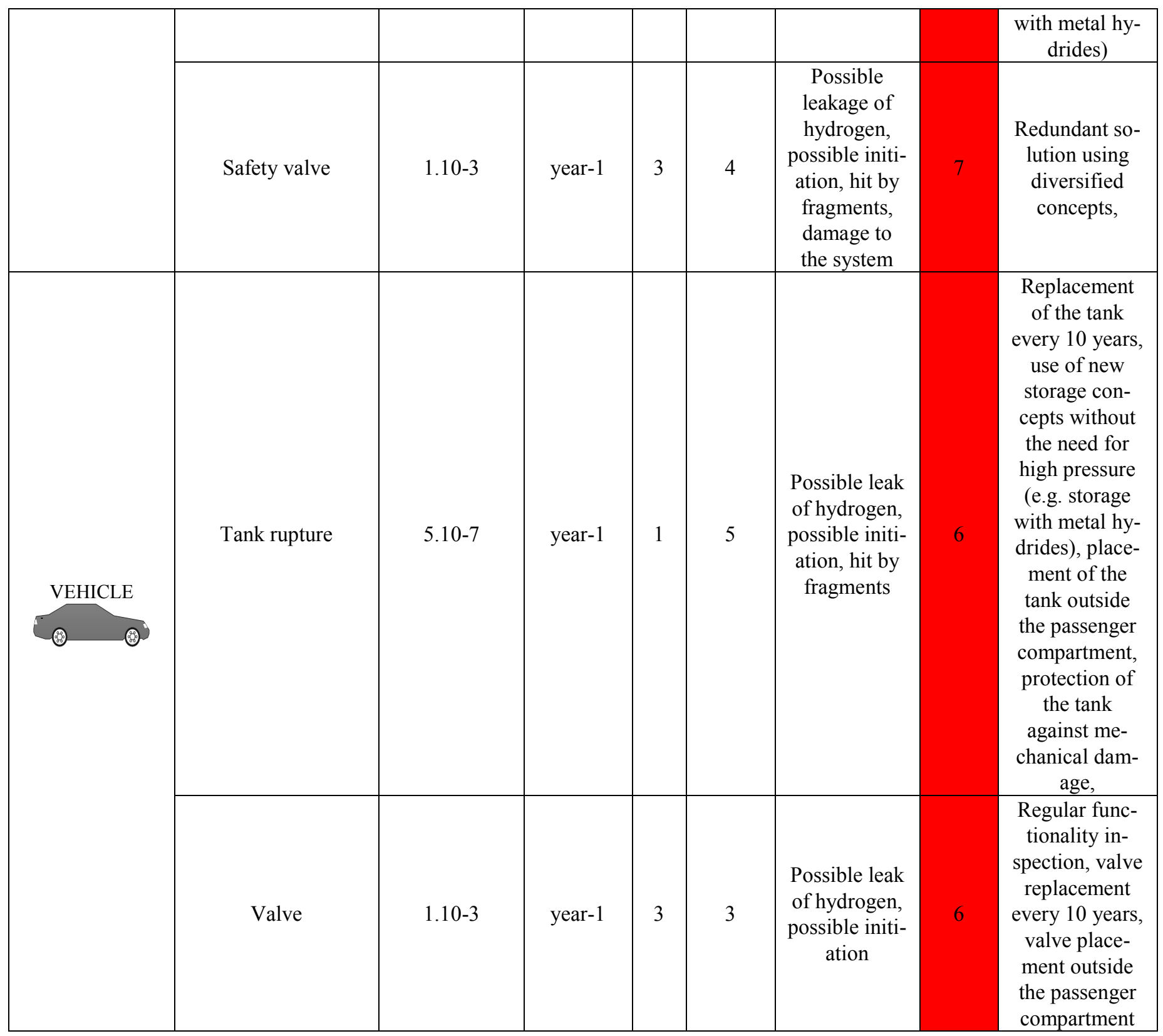

Tab. 4 Management system model for the most severe risk 


\subsection{Risks in mobile hydrogen technologies for Security area}

The risks arising from hydrogen technology application in mobility for the Security area (Civil security) can be assigned to the following processes - Fig.8:

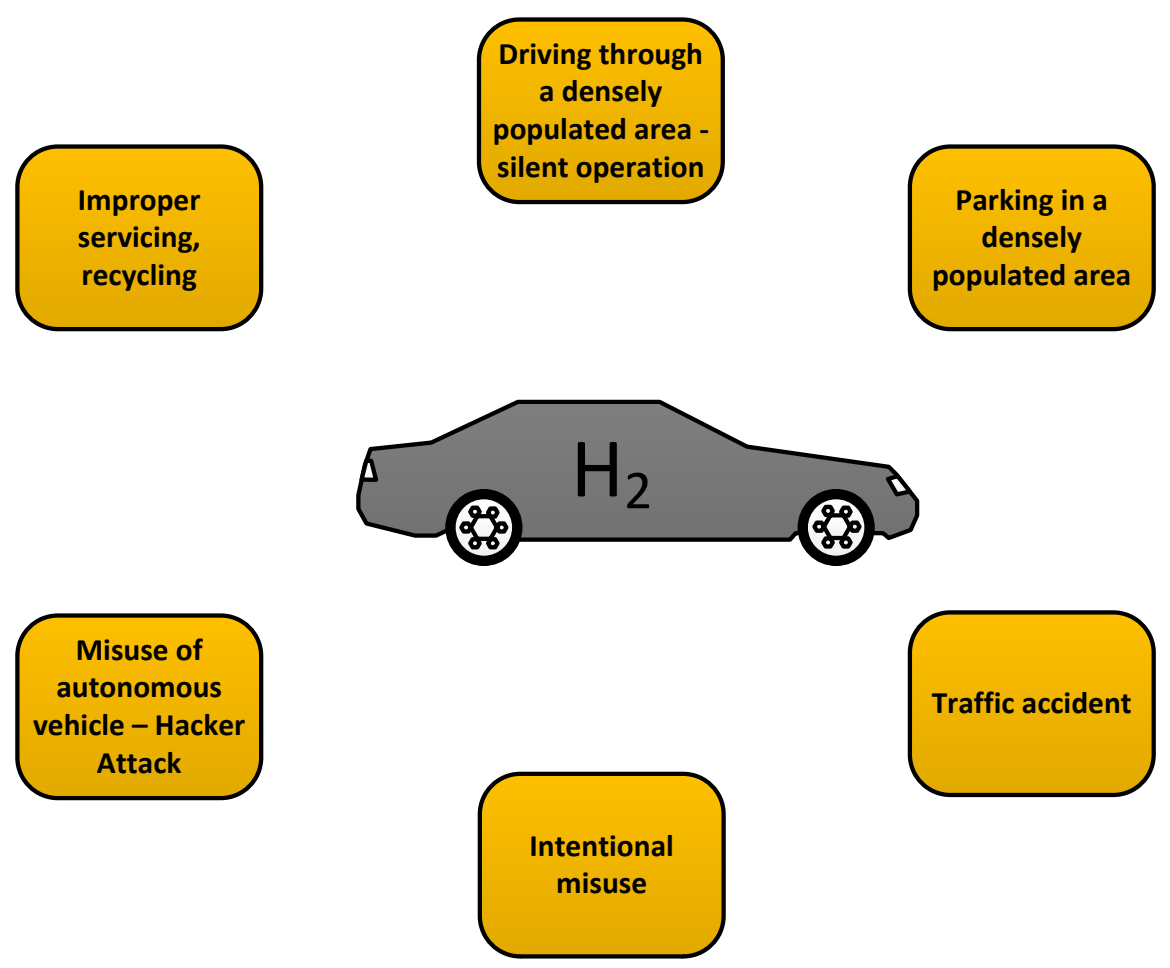

Fig. 1 Hydrogen technology risk for the Security area

Improper servicing, recycling - due to the necessary availability of services and the expected use of the existing service centers for individual car brands, it is necessary to consider the service of hydrogen cars. Considering that several people may be present at the car service centre when the staff is manipulating with the hydrogen system components, the risk of leakage and subsequent incident initiation is increased. Service centers are often located in places with a large number of uninterested persons around. It is also possible to characterize the risk involved in recycling of these cars after their lifecycle.

Driving through a densely populated area - silent operation - driving hydrogen cars in cities with the increased number of people around the car poses a danger. 
Since the hydrogen fuel cell produces very little noise during its operation and the electric power obtained from it drives the vehicle by electromotors that are also quiet, it can be assumed that with the spread of hydrogen cars the risk of pedestrian injuries will increase.

Parking in a densely populated area (city centers, residential areas, above/underground garages, shopping centers) - Hydrogen leakage may occur during parking, with the subsequent trigger of an explosion, which may endanger people in the vicinity. The explosion has the potential to subsequently trigger a domino effect - e.g. collapsing of a building, subsequent fire - they can endanger many more people around than those transported in the respective car.

Traffic accident - location of a motor car is an important factor in case of car accident. Leakage and subsequent initiation of hydrogen in an inappropriate environment (tunnel, ferry, car train) will have far more serious consequences than would be the case in open space traffic accident where hydrogen can dissolve rapidly into the atmosphere.

Intentional misuse - In case of intentional misuse, the dangers are comparable to those with internal combustion engines. It may result in the deliberate knocking down of persons, or the intentional damage to the car in order to endanger and damage the property or the health of the persons. With the upcoming autonomous cars, it is also worth considering the possible hacker attacks on vehicle control software for communication with the environment.

\section{Summary / Conclusion /}

Hydrogen represents the future of sustainable mobility on Earth. Its use will entail risks resulting from different properties from fossil fuels or electric vehicles. Due to its flammability and explosiveness in a wide range of concentration when mixed with air, hydrogen poses a risk to both Safety and Security. Its chemical and physical properties, the need for storage under high pressure, or the use of special methods represent increased demands on the used propulsion technology. It also brings a modified approach in the hydrogen production, car production, operation, servicing as well as recycling. The extent of hydrogen leakage in operating conditions of automotive technologies and its localization can significantly affect the consequences of potential initiation and incidents as well. The risk analysis has highlighted the vehicle's construction nodes, which we need to pay increased attention to, and subsequently develop technical devices and systems that use, e.g. redundancy elements or fail-safe solutions.

Zero risk, i.e. $100 \%$ safety, does not exist with any technical device. However, appropriate measures can be taken to ensure that the risk of hydrogen technologies can be considered acceptable in order to create conditions for the development of technology which will take into account the environmental aspects of the mobility of the future.

The article was created within framework of scientific research tasks titled ... 


\section{Acknowledgement}

This paper was developed within the project APVV - 0337-11 The research on new and emerging risks of industrial technologies within integrated security as a prerequisite for the management of sustainable development,

VEGA 1/0150/15 Development of methods for implementation and verification of integrated systems for safety of machines, machine systems and industrial technologies

and this paper was elaborated also thanks to the support, which was offered in the framework of the operational program Research and Development for the project: Research Centre of Integration Efficiency for Combined Systems of the Renewable Energy Sources, with the code ITMS: 26220220064, which is cofinanced from the European Fund of Regional Develompent."

\section{References}

[1] KONEČNÝ B.: Hydrogen technology risks - application for mobile technology. Dissertation thesis, Faculty of Mechanical Engineering,Technical Universi ty of Košice, 2017

[2] KATER, John., How Hydrogen Cars Work and Developments of Hydrogen Fuel Cells., [online], [cit.2015-12-1]. Available on: http://www.autosvenue.com/howhydrogen-cars-work-and-developments-of-hydrogen-fuel-cells/! prettyPhoto

[3] HUITT, William M., Piping material for hydrogen service, [online], [cit.2015-29-1] Available on: http://www.wmhuittco.com/images/Hydrogen_Piping.pdf

[4] ORAVEC, Milan., VARGOVÁ, Slavomíra., GLATZ, Juraj.,: Severe industrial incidents - risk assessment methods. TUKE, Košice 2014, ISBN 978-80-553-1932-2

[5] Refuelling hydrogen systems., Hydrogen refuelling nozzle., www.weh.com., [online] [cit.2015-29-1]. Available on: http://www.weh.com/sites/default/files/tk16_h2_db_e.pdf

[6] SINAY, Juraj.: Safety management in a competitive businesss environment; Taylor\&Francis Group, 2014; ISBN 9781482203851 